\title{
Cobalamin Deficiency in Elderly Patients: A Personal View
}

\author{
Emmanuel Andrès, ${ }^{1}$ Thomas Vogel, ${ }^{2}$ Laure Federici, ${ }^{1}$ Jacques Zimmer, ${ }^{3}$ \\ Ecaterina Ciobanu, ${ }^{1}$ and Georges Kaltenbach ${ }^{2}$ \\ ${ }^{1}$ Department of Internal Medicine, Diabetes, and Metabolic Diseases, University Hospital of Strasbourg, 67091 Strasbourg, France \\ ${ }^{2}$ Department of Internal Medicine and Geriatrics, University Hospital of Strasbourg, 67091 Strasbourg, France \\ ${ }^{3}$ Laboratoire d'Immunogénétique-Allergologie, Centre de Recherche Public de la Santé (CRP-Santé) de Luxembourg, \\ 1526 Luxembourg, Luxembourg \\ Correspondence should be addressed to Emmanuel Andrès, emmanuel.andres@chru-strasbourg.fr
}

Received 3 February 2008; Accepted 18 April 2008

Recommended by Irene Rea

Cobalamin (vitamin B12) deficiency is particularly common in the elderly ( $>65$ years of age) but is often unrecognized because its clinical manifestations are subtle; however, they are also potentially serious, particularly from a neuropsychiatric and hematological perspective. In the elderly, the main causes of cobalamin deficiency are pernicious anemia and food-cobalamin malabsorption. Food-cobalamin malabsorption syndrome is a disorder characterized by the inability to release cobalamin from food or its binding proteins. This syndrome is usually caused by atrophic gastritis, related or unrelated to Helicobacter pylori infection, and longterm ingestion of antacids and biguanides. Management of cobalamin deficiency with cobalamin injections is currently well documented but new routes of cobalamin administration (oral and nasal) are being studied, especially oral cobalamin therapy for food-cobalamin malabsorption.

Copyright ( $\odot 2008$ Emmanuel Andrès et al. This is an open access article distributed under the Creative Commons Attribution License, which permits unrestricted use, distribution, and reproduction in any medium, provided the original work is properly cited.

\section{Introduction}

Cobalamin or vitamin B12 deficiency is common in elderly patients [1] but is often unrecognized or not investigated because the clinical manifestations of cobalamin deficiency are subtle. However, the complications of cobalamin deficiency, particularly the neuropsychiatric and hematological [1-4], are potentially serious and therefore require investigation in all patients who present with vitamin or nutritional deficiency. Classic disorders such as pernicious anemia are the cause of cobalamin deficiency in only a limited number of patients, especially elderly patients [4]. A more common problem is food-cobalamin malabsorption, a disorder characterized by the inability to release cobalamin from food or its binding proteins [4]. This review summarizes the current knowledge on cobalamin deficiency, with a particular focus on food-cobalamin malabsorption and oral cobalamin therapy.

\section{Definition of Cobalamin Deficiency}

Literature of the last ten years has provided several definitions of cobalamin deficiency [5-7]. The definitions of cobalamin deficiency used in this review are shown in Table 1 $[7,8]$. To date, cobalamin deficiency is often defined in terms of the serum concentration of cobalamin and of homocysteine and methyl malonic acid, two components of the cobalamin metabolic pathway, (Figure 1) but in clinical practice, no single test has emerged as the gold standard for diagnosis of cobalamin deficiency especially in elderly patients. Moreover, the major diagnostic challenge remains patients who develop subtle cobalamin deficiency, often without hematological abnormalities (usefulness of an early treatment to prevent irreversible neurological damages) [4]. In the future, new serum cobalamin assay kits (e.g., the holotranscobalamin assay kit) might perhaps replace older assay kits and should become the standard for testing $[6,9]$.

\section{Epidemiology of Cobalamin Deficiency}

Epidemiological studies show that in the general population of industrialized countries, cobalamin deficiency has a prevalence of around 2 to $20 \%$, depending on the definition of cobalamin deficiency used $[4,9]$. The Framingham study demonstrated a prevalence of $12 \%$ among elderly people 


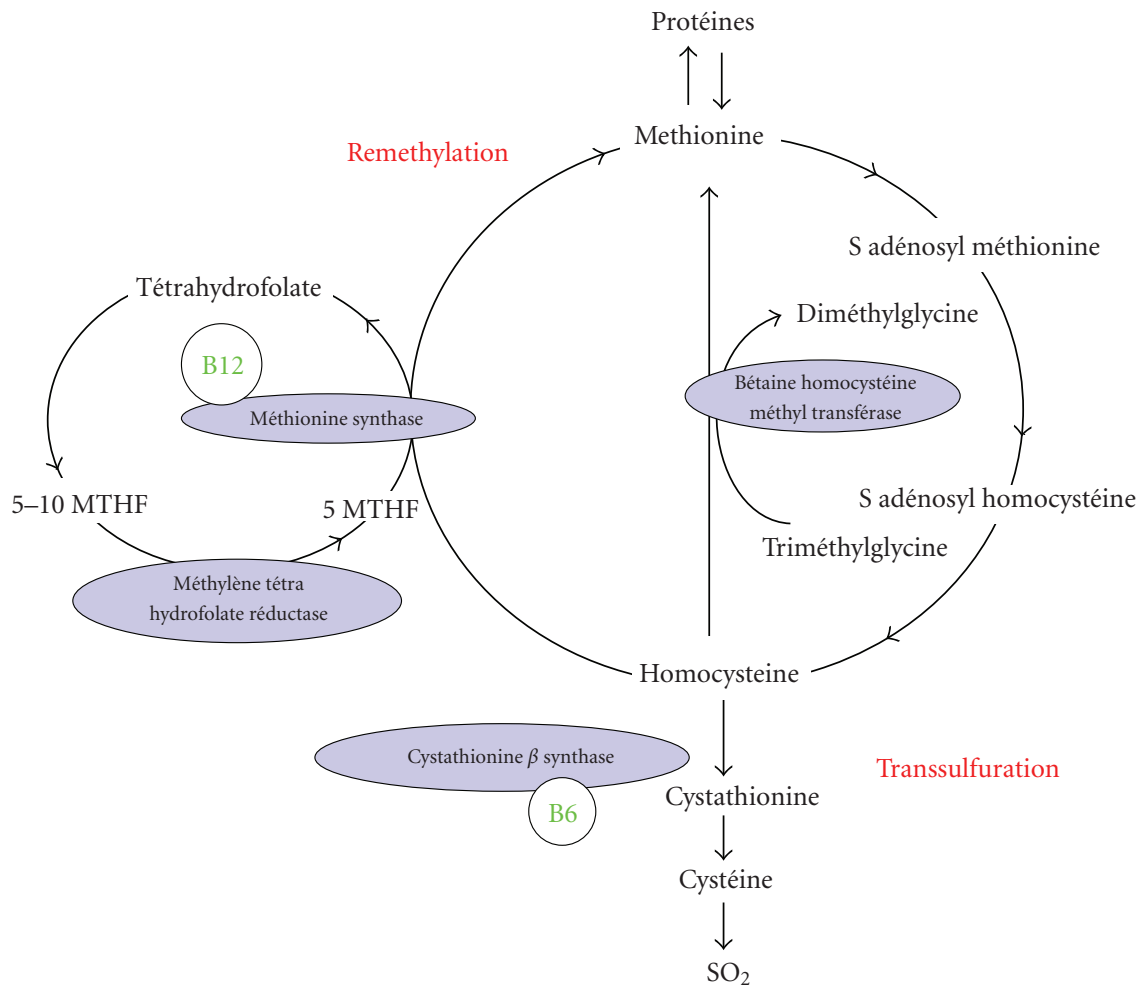

FIGURE 1: Cellular impact of cobalamin deficiency.

living in the community [10]. Other studies focusing on elderly people, particularly those who are in institutions or who are sick and malnourished, have suggested a higher prevalence of at least $30 \%[11,12]$. Using the definition in Table 1 (serum cobalamin levels $<150 \mathrm{pmol} / \mathrm{L}[<200 \mathrm{pg} / \mathrm{mL}]$ on 2 separate occasions), we found that cobalamin deficiency had a prevalence of $5 \%$ in a group of patients followed or hospitalized in a tertiary reference hospital [8]. We also documented that around $4 \%$ of the anemia were related to a cobalamin deficiency in a population of 300 consecutive anemia hospitalized in our department (tertiary reference center) [8]. In the NHANES III study, $34 \%$ of all anemia in elderly patients is caused by folate, cobalamin, or iron deficiency, alone or in combination (nutritient-deficiency anemia) [8].

\section{Cobalamin Metabolism and Function}

Cobalamin metabolism is complex and is made up of many processes, defects in any one of which can lead to cobalamin deficiency $[4,13-15]$. The different stages of cobalamin metabolism and corresponding causes of cobalamin deficiency are shown in Table 2. Once metabolized, cobalamin is a cofactor and coenzyme for many biochemical reactions, including DNA synthesis, methionine synthesis from homocysteine, and conversion of propionyl into succinyl coenzyme A from methyl malonate $[4,9]$. In a clinical setting, cobalamin absorption is measured imperfectly by the Schilling test $[4,8]$. A typical Western diet contributes 3-30 $\mu \mathrm{g}$ of cobalamin per day $[13,15]$ toward the recommended dietary allowance of $2.4 \mu \mathrm{g} /$ day for adults and 2.6 to $2.8 \mu \mathrm{g} /$ day
Table 1: Definitions of cobalamin (vitamin B12) deficiency [5-7].

(i) Serum cobalamin levels $<150 \mathrm{pmol} / \mathrm{L}$ and clinical features and/or hematological anomalies related to cobalamin deficiency

(ii) Serum cobalamin levels $<150 \mathrm{pmol} / \mathrm{L}(<200 \mathrm{pg} / \mathrm{mL})$ on 2 separate occasions

(iii) Serum cobalamin levels $<150 \mathrm{pmol} / \mathrm{L}$ and total serum homocysteine levels $>13 \mu \mathrm{mol} / \mathrm{L}$ or methylmalonic acid levels $>0.4 \mu \mathrm{mol} / \mathrm{L}$ (in the absence of renal failure and folate and vitamin B6 deficiencies)

(iv) Low serum holotranscobalamin levels $<35 \mathrm{pmol} / \mathrm{L}$

during pregnancy [16]. The 5-10 year delay between the onset of cobalamin deficiency and the development of clinical illness is directly attributable to hepatic stores of cobalamin $(>1.5 \mathrm{mg})$ and the enterohepatic cycle $[4,13]$. Between 1-5\% of free cobalamin (or crystalline cobalamin) is absorbed along the entire intestine by passive diffusion. This absorption explains the mechanism underlying oral treatment of cobalamin deficiencies $[17,18]$.

\section{Classical Causes of Cobalamin Deficiency}

In elderly patients, cobalamin deficiency is classically caused by pernicious anemia and food-cobalamin malabsorption $[1,11,14]$. The principal characteristics of pernicious anemia have been reported in detail in several reviews [19-21]. Diagnosis of pernicious anemia is based on the presence 
TABLE 2: Stages of cobalamin metabolism and corresponding causes of cobalamin deficiency [13, 15].

Stages and factors involved in cobalamin metabolism

Ingestion of food

Digestion, which involves haptocorrin, gastric secretions $(\mathrm{HCl}$ and pepsin), intrinsic factor, pancreatic and biliary secretions, and the enterohepatic cycle

Absorption, which brings into play intrinsic factor and cubilin

Transportation by transcobalamins

Intracellular metabolism by various intracellular enzymes

$\mathrm{HCl}=$ hydrochloric acid
Causes of cobalamin deficiency

Strict vegetarianism (patients who are sick in institutions or in psychiatric hospitals)

Gastrectomy, pernicious anemia, and food-cobalamin malabsorption

Ileal resection, malabsorption, pernicious anemia, and food-cobalamin malabsorption

Congenital deficiency in transcobalamin II

Congenital deficiency in various intracellular enzymes

TABLe 3: Food-cobalamin malabsorption syndrome $[4,14,15]$.

\begin{tabular}{ll}
\hline \multicolumn{1}{c}{ Criteria for food-cobalamin malabsorption } & Associated conditions or agents \\
\hline - Low-serum cobalamin (vitamin B12) levels & - Gastric disease: atrophic gastritis, type A atrophic gas- \\
- Normal results of Schilling test using free cyanocobalamin labeled & tritis, gastric disease associated with Helicobacter pylo- \\
with cobalt-58, or abnormal results of derived Schilling test ${ }^{\ddagger}$ & ri infection, partial gastrectomy, gastric by-pass, and \\
- No anti-intrinsic factor antibodies & vagotomy \\
- No dietary cobalamin deficiency & - Pancreatic insufficiency: alcohol \\
& - Gastric or intestinal bacterial overgrowth: achlorhyd- \\
ria, tropical sprue, Ogylvie’s syndrome, and HIV & - Drugs: antacids (H2-receptor antagonists and proton- \\
& pump inhibitors) or biguanides (metformin) \\
& - Alcohol abuse \\
& - Sjögren's syndrome, systemic sclerosis \\
\end{tabular}

${ }^{\ddagger}$ Derived Schilling tests use food-bound cobalamin (e.g., egg yolk, chicken, and fish proteins).

of (1) intrinsic factor antibodies in serum (specificity: $>98 \%$, sensibility: around 50\%) and/or (2) autoimmune atrophic gastritis (presence of Helicobacter pylori infection in gastric biopsies is an exclusion factor) $[15,19]$. Cobalamin deficiency caused by dietary deficiency or malabsorption is rare. Dietary causes of deficiency are limited to elderly people who are already malnourished. This mainly concerns elderly patients living in institutions or in psychiatric hospitals $[4,13]$. Since the 1980 s, the malabsorption of cobalamin has become rarer, owing mainly to the decreasing frequency of gastrectomy and surgical resection of the terminal small intestine $[4,14]$. Several disorders commonly seen in gastroenterology practice might, however, be associated with cobalamin malabsorption. These include deficiency in the exocrine function of the pancreas after chronic pancreatitis (usually alcoholic), lymphomas or tuberculosis (of the intestine), Crohn's disease, Whipple's disease, and uncommonly celiac disease $[11,15]$.

\section{Food-Cobalamin Malabsorption}

First, well-described by Carmel in 1995 [22], the foodcobalamin malabsorption is a syndrome characterized by the inability to release cobalamin from food or intestinal transport proteins, particularly in the presence of hypochlorhy- dria, in which the absorption of "unbound" cobalamin is normal. As various studies have shown [14, 22, 23], this syndrome is defined by cobalamin deficiency in the presence of sufficient food-cobalamin intake and normal Schilling test results, which rules out malabsorption or pernicious anemia. The principal characteristics of this syndrome are listed in Table 3. In theory, indisputable evidence of food-cobalamin malabsorption comes from using a modified Schilling test, which uses radioactive cobalamin bound to animal proteins (e.g., salmon, trout) and reveals malabsorption when the results of a standard Schilling test are normal $[4,14,23]$.

Food-cobalamin malabsorption has been found to be the leading cause of cobalamin malabsorption, especially in elderly patients $[4,11,22]$. In our experience (300 patients with a documented cobalamin deficiency), foodcobalamin malabsorption accounts for about $60-70 \%$ of the cases of cobalamin deficiency in elderly patients, whereas pernicious anemia accounted for only $15-25 \%[14,23]$. Some authors have speculated about the reality and significance of cobalamin deficiency related to food-cobalamin malabsorption [4], because many patients have only mild clinical or hematological features. Several of our patients, however, [14] had significant features classically associated with pernicious anemia, including polyneuropathy, confusion, dementia, medullar-combined sclerosis, anemia, and a pancytopenia. Nevertheless, the partial nature of 
TABLe 4: Main clinical features of cobalamin deficiency $[2,4,14,15,34-36]$.

\begin{tabular}{|c|c|c|c|}
\hline $\begin{array}{l}\text { Hematological } \\
\text { manifestations }\end{array}$ & $\begin{array}{l}\text { Neuro-psychiatric } \\
\text { manifestations }\end{array}$ & Digestive manifestations & Other manifestations \\
\hline $\begin{array}{l}\text { - Frequent: macrocytosis, hyper- } \\
\text { segmentation of the neutrophils, } \\
\text { aregenerative macrocytary ane- } \\
\text { mia, LDH and bilirubin eleva- } \\
\text { tion, medullary megaloblastosis } \\
\text { "(blue spinal cord)" } \\
\text { - Rare: isolated thrombocytopenia } \\
\text { and neutropenia, pancytopenia } \\
\text { - Very rare: hemolytic anemia, } \\
\text { thrombotic microangiopathy } \\
\text { (presence of schistocytes) }\end{array}$ & $\begin{array}{l}\text { - Frequent: polyneurites (espe- } \\
\text { cially sensitive ones), ataxia, } \\
\text { Babinski's phenomenon } \\
\text { - Classic: combined sclerosis } \\
\text { of the spinal cord } \\
\text { - Rare: cerebellar syndromes } \\
\text { affecting the cranial nerves } \\
\text { including optic neuritis, op- } \\
\text { tic atrophy, urinary, and/or } \\
\text { fecal incontinence } \\
\text { - Under study: changes in the } \\
\text { higher functions, even de- } \\
\text { mentia, stroke and athero- } \\
\text { sclerosis (hyperhomocyst- } \\
\text { einemia), parkinsonian syn- } \\
\text { dromes, depression, multi- } \\
\text { ple sclerosis }\end{array}$ & $\begin{array}{l}\text { - Classic: Hunter’s glossitis, jaun- } \\
\text { dice, LDH and bilirubin eleva- } \\
\text { tion “(intramedullary destruc- } \\
\text { tion)” } \\
\text { - Debatable: abdominal pain, } \\
\text { dyspepsia, nausea, vomiting, } \\
\text { diarrhea, disturbances in intes- } \\
\text { tinal functioning } \\
\text { - Rare: resistant and recurring } \\
\text { mucocutaneous ulcers cobala- } \\
\text { min deficiency }\end{array}$ & $\begin{array}{l}\text { - Under study: atrophy of the vag- } \\
\text { inal mucosa and chronic vaginal } \\
\text { and urinary infections (especial- } \\
\text { ly mycosis), hypofertility and re- } \\
\text { peated miscarriages (connection } \\
\text { with cobalamin deficiency under } \\
\text { study), venous thromboembolic } \\
\text { disease, angina (hyperhomocyst- } \\
\text { einemia), osteoporosis }\end{array}$ \\
\hline
\end{tabular}

this form of malabsorption might produce a more slowly progressive depletion of cobalamin than does the more complete malabsorption engendered by disruption of intrinsic factor-mediated absorption. The slower progression of depletion probably explains why mild preclinical deficiency is associated with food-cobalamin malabsorption more often than with pernicious anemia $[4,14]$.

Food-cobalamin malabsorption is caused primarily by atrophic gastritis [14]. Achlorhydria hampers the extraction of cobalamin from protein food sources. Over $40 \%$ of patients older than 80 years of age have gastric atrophy that might or might not be related to Helicobacter pylori infection $[11,24]$. Other factors that contribute to food-cobalamin malabsorption in elderly people include chronic carriage of $H$. pylori and intestinal microbial proliferation (in which case cobalamin deficiency can be corrected by antibiotic treatment) $[24,25]$; long-term ingestion of antiacids, including H2-receptor antagonists and proton-pump inhibitors $[26,27]$, particularly among patients with Zollinger-Ellison syndrome [28, 29], and biguanides (metformin) [30-32]; chronic alcoholism; surgery or gastric reconstruction (e.g., bypass surgery for obesity); partial pancreatic exocrine failure $[4,14]$, and Sjögren's syndrome or systemic sclerosis [33] (Table 3). In a series of 92 elderly patients (mean age: 76 years) with food-cobalamin malabsorption [14], we have reported at least one of these associated conditions or agents in $60 \%$ of the patients. These conditions mainly include atrophic gastritis ( \pm H. pylori infection) in $30 \%$ of the patients and long-term metformin or antacid intake in $20 \%$ of the elderly patients.

\section{Clinical Manifestations of Cobalamin Deficiency}

The primary clinical manifestations of cobalamin deficiency are described in Table 4. They are highly polymorphic and of varying severity ranging from common sensory neuropathy and isolated anomalies of macrocytosis and hypersegmenta- tion of neutrophils, to severe disorders, including combined sclerosis of the spinal cord, hemolytic anemia, and even pancytopenia $[2,14,34-36]$. In the aforementioned series of 92 patients with food-cobalamin malabsorption [14], we have found at least one clinical feature or hematological abnormalities in, respectively, $70 \%$ and $76 \%$ of the patients. Cobalamin deficiency appears to be more common among patients who have a variety of chronic neurologic conditions such as dementia, Alzheimer's disease, stroke, Parkinson's disease, and depression, although it is unclear if these are causal relationships $[4,37]$. In our own studies in which we administered cobalamin to patients with dementia, improvement was not observed [8, 14]. Other studies have had similar results $[1,2,9]$. At this time, a causal role of cobalamin in these conditions remains speculative.

\section{Classical Treatment of Cobalamin Deficiency}

The classic treatment for cobalamin deficiency, particularly when the cause is not dietary deficiency, is parenteral administration-in most countries intramuscular injection-of this vitamin (in the form of cyanocobalamin and, more rarely, hydroxy or methyl cobalamin) $[1,17$, 18, 34]. However, traditions concerning both dose and schedule of administration vary considerably. In France, the recommended practice is to build up the tissue stores of the vitamin quickly and correct serum cobalamin hypovitaminosis, particularly in the case of pernicious anemia. The treatment involves the administration of $1000 \mu \mathrm{g}$ of cyanocobalamin per day for 1 week, followed by $1000 \mu \mathrm{g}$ per week for 1 month, followed by $1000 \mu \mathrm{g}$ per month, normally for the rest of the patient's life $[11,19]$. In USA and UK, dosages ranging from 100 to $1000 \mu \mathrm{g}$ per month [or every 23 months when hydroxocobalamin is given] are used during the rest of the patient's life $[4,17]$. Hydroxocobalamin may have several advantages due to a better tissular retention and storage. Additionally, recent works concern oral cobalamin therapy through food fortification $[3,11]$. 
TABLE 5: Experience of oral cobalamin therapy for food-cobalamin malabsorption in the university hospital of Strasbourg, France.

Study characteristics (number of patients)

Open prospective study of well-documented cobalamin deficiency related to food-cobalamin malabsorption $(n$ $=10$ )
Therapeutic modalities

Results

- Normalization of serum cobalamin levels in $80 \%$ of the patients

- Significant increase of hemoglobin Oral crystalline cyanocobalamin: $650 \mu \mathrm{g} \quad(\mathrm{Hb})$ levels (mean of $1.9 \mathrm{~g} / \mathrm{dL}$ ) and per day during at least 3 months decrease of mean erythrocyte cell volume (ECV) (mean of $7.8 \mathrm{fL}$ )

- Improvement of clinical abnormalities in $20 \%$ of the patients

Open prospective study of low-cobalamin levels not related to pernicious anemia $(n=20)$

Oral crystalline cyanocobalamin: between $1000 \mu \mathrm{g}$ per day during at least 1 week
- Normalization of serum cobalamin levels in $85 \%$ of the patients - No adverse effect

- Normalization of serum cobalamin Oral crystalline cyanocobalamin: between 1000 and $250 \mu \mathrm{g}$ per day during 1 month

levels in $87 \%$ of the patients

- Dose effect: effectiveness dose of cobalamin $\geq 500 \mu \mathrm{g}$ per day
- No adverse effect

- Significant increase of $\mathrm{Hb}$ levels (mean of $0.6 \mathrm{~g} / \mathrm{dL}$ ) and decrease of ECV (mean of $3 \mathrm{fL}$ ); normalization of $\mathrm{Hb}$ levels and $\mathrm{ECV}$ in $54 \%$ and $100 \%$ of the patients, respectively

Oral crystalline cyanocobalamin: between 1000 and $125 \mu \mathrm{g}$ per day during amin levels not related to pernicious anemia $(n=30)$
- Normalization of serum cobalamin levels in all patients with at least a dose of vitamin $\geq 250 \mu$ g per day

- Dose effect: effectiveness dose of cobalamin $\geq 500 \mu \mathrm{g}$ per day

- No adverse effect

- Significant increase of serum cobalamin levels in $90 \%$ of the patients (mean of $117.4 \mathrm{pg} / \mathrm{mL}$ )

- Significant increase of $\mathrm{Hb}$ levels (mean of $2.45 \mathrm{~g} / \mathrm{dL}$ ) and decrease of ECV (mean of $10.4 \mathrm{fL}$ )

- Improvement of clinical abnormalities in $30 \%$ of the patients

\section{Oral Cobalamin Therapy}

Since cobalamin is absorbed by intrinsic factor-independent passive diffusion (1\% of oral cobalamin), daily high-dose oral cyanocobalamin can induce and maintain remissions in patients with megaloblastic anemia [15]. In cases of cobalamin deficiency other than those caused by nutritional deficiency, alternative routes of cobalamin administration have been used: oral $[17,18,38-44]$ and nasal $[45,46]$. These other routes of administration have been proposed as a way of avoiding the discomfort, inconvenience, and cost of monthly injections. Our working group has developed an effective oral treatment of food-cobalamin malabsorption [40-43] and for pernicious anemia [47] using crystalline cobalamin (cyanocobalamin). Our principal studies of oral cobalamin treatment (open, not randomized studies) are described in Table 5 [40-43,47]. These data confirm the previously reported efficacy of oral crystalline cyanocobalamin, especially in food-cobalamin therapy $[18,36,38]$. All of our patients who were treated orally corrected their cobalamin levels and at least two-thirds corrected their hematological abnormalities [40-43, 47]. Moreover, onethird of patients experienced a clinical improvement on oral treatment. In most cases of food-cobalamin malabsorption, "low" cobalamin doses (i.e., 125-1000 $\mu$ g of oral crystalline cyanocobalamin per day) were used. These data is in accordance with the results of the two prospective randomized-controlled studies comparing oral cobalamin with intramuscular cobalamin therapy $[17,39]$. A systematic review of randomized-controlled trials by the Vitamin B12 Cochrane Group supports the efficacy of oral cobalamin therapy, with a dose between 1000 and $2000 \mu \mathrm{g}$ given initially daily and then weekly [48]. In this analysis, serum cobalamin levels increased significantly in patients receiving oral cobalamin and both groups of patients (receiving oral and intramuscular treatment) had neurological improvement. The Cochrane group concludes that daily oral therapy "may be as effective as intramuscular administration in obtaining short term haematological and neurological responses in cobalamin deficient patients" [48]. Nevertheless to our 
knowledge, the effect of oral cobalamin treatment in patients presenting severe neurological manifestations has not yet been adequately documented. Thus until this has been done parenteral cobalamin therapy is still to be recommended for such patients. In a randomized, parallel-group, double-blind, dose-finding trial, Eussen et al. showed that the lowest dose of oral cyanocobalamin required to normalize mild cobalamin deficiency is more than 200 times the recommended dietary allowance of approximately $3 \mu \mathrm{g}$ daily (i.e., $>500 \mu \mathrm{g}$ per day) [49]. The procedure for oral cobalamin treatment has, however, not been completely validated yet in real life, particularly the long-term efficacy [50]. To date, as several authors suggest, oral cobalamin therapy remains one of "medicine's best kept secrets" [51]. Since loading doses of cobalamin far exceed physiologic requirements, clinical responses may result from pharmacologic effects on either cobalamin-related processes or on cellular functions completely unrelated to the known biochemical actions of cobalamin [52]. As a result, blood cobalamin, methylmalonic acid and homocysteine values often fail to predict whether or not a patient will respond to cobalamin therapy [53]. Nevertheless, the following can be proposed: ongoing supplementation until associated disorders are corrected (e.g., by halting the ingestion of the offending medication or exogenosis, or by treating $H$. pylori infection or pancreatic exocrine failure), lifelong administration or, when applicable, sequential administration [54].

\section{Acknowledgments}

The authors would like to thank Professor Marc Imler and Jean-Louis Schlienger who initiated this work. The research on cobalamin deficiency was supported by a Grant of the Fondation de France (Prix Robert et Jacqueline Zittoun 2004).

\section{References}

[1] J. H. Matthews, "12 cobalamin and folate deficiency in the elderly," Baillière's Clinical Haematology, vol. 8, no. 3, pp. 679697, 1995.

[2] S. P. Stabler, R. H. Allen, D. G. Savage, and J. Lindenbaum, "Clinical spectrum and diagnosis of cobalamin deficiency," Blood, vol. 76, no. 5, pp. 871-881, 1990.

[3] E. Reynolds, "Vitamin $B_{12}$, folic acid, and the nervous system," The Lancet Neurology, vol. 5, no. 11, pp. 949-960, 2006.

[4] R. Carmel, "Current concepts in cobalamin deficiency," Annual Review of Medicine, vol. 51, pp. 357-375, 2000.

[5] C. F. Snow, "Laboratory diagnosis of vitamin $\mathrm{B}_{12}$ and folate deficiency. A guide for the primary care physician," Archives of Internal Medicine, vol. 159, no. 12, pp. 1289-1298, 1999.

[6] J. Zittoun and R. Zittoun, "Modern clinical testing strategies in cobalamin and folate deficiency," Seminars in Hematology, vol. 36, no. 1, pp. 35-46, 1999.

[7] G. G. Klee, "Cobalamin and folate evaluation: measurements of methylmalonic acid and homocystein vs vitamin $\mathrm{B}_{12}$ and folate," Clinical Chemistry, vol. 46, pp. 1277-1283, 2000.

[8] E. Andrès, L. Federici, K. Serraj, and G. Kaltenbach, "Update of nutritient-deficiency anemia in elderly patients," European Journal of Internal Medicine. In press.
[9] H. V. Markle and D. C. Greenway, "Cobalamin," Critical Reviews in Clinical Laboratory Sciences, vol. 33, no. 4, pp. 247356, 1996.

[10] J. Lindenbaum, I. H. Rosenberg, P. W. Wilson, S. P. Stabler, and R. H. Allen, "Prevalence of cobalamin deficiency in the Framingham elderly population," American Journal of Clinical Nutrition, vol. 60, no. 1, pp. 2-11, 1994.

[11] A.-M. Hvas and E. Nexo, "Diagnosis and treatment of vitamin $\mathrm{B}_{12}$ deficiency. An update," Haematologica, vol. 91, no. 11, pp. 1506-1512, 2006.

[12] D. Z. van Asselt, H. J. Blom, R. Zuiderent, et al., "Clinical significance of low cobalamin levels in older hospital patients," The Netherlands Journal of Medicine, vol. 57, no. 2, pp. 41-49, 2000.

[13] J. P. Nicolas and J. L. Guéant, "Absorption, distribution et excrétion de la vitamine $\mathrm{B}_{12}$," Annales de Gastroenterologie et d'Hepatologie, vol. 30, no. 6, pp. 270-282, 1994.

[14] E. Andrès, S. Affenberger, S. Vinzio, et al., "Food-cobalamin malabsorption in elderly patients: clinical manifestations and treatment," The American Journal of Medicine, vol. 118, no. 10, pp. 1154-1159, 2005.

[15] E. Andrès, N. H. Loukili, E. Noel, et al., "Vitamin $B_{12}$ (cobalamin) deficiency in elderly patients," Canadian Medical Association Journal, vol. 171, no. 3, pp. 251-259, 2004.

[16] Food and Nutrition Board, Institute of Medicine, Dietary Reference Intakes for Thiamin, Riboflavin, Niacin, Vitamin $B_{6}$, Folate, Vitamin $B_{12}$, Pantothenic Acid, Biotin, and Choline, National Academies Press, Washington, DC, USA, 1998.

[17] A. M. Kuzminski, E. J. Del Giacco, R. H. Allen, S. P. Stabler, and J. Lindenbaum, "Effective treatment of cobalamin deficiency with oral cobalamin,” Blood, vol. 92, no. 4, pp. 1191-1198, 1998.

[18] L. A. Lane and C. Rojas-Fernandez, "Treatment of vitamin $\mathrm{B}_{12}$-deficiency anemia: oral versus parenteral therapy," The Annals of Pharmacotherapy, vol. 36, no. 7, pp. 1268-1272, 2002.

[19] N. H. Loukili, E. Noel, G. Blaison, et al., "Données actuelles sur la maladie de Biermer. À propos d'une étude rétrospective de 49 observations," La Revue de Médecine Interne, vol. 25, no. 8, pp. 556-561, 2004.

[20] B.-H. Toh, I. R. van Driel, and P. A. Gleeson, "Pernicious anemia," The New England Journal of Medicine, vol. 337, no. 20, pp. 1441-1448, 1997.

[21] J. C. W. Chan, H. S. Y. Liu, B. C. S. Kho, et al., "Pernicious anemia in Chinese: a study of 181 patients in a Hong Kong hospital," Medicine, vol. 85, no. 3, pp. 129-138, 2006.

[22] R. Carmel, "10 Malabsorption of food-cobalamin," Baillière's Clinical Haematology, vol. 8, no. 3, pp. 639-655, 1995.

[23] E. Andrès, E. Noel, and G. Kaltenbach, "Carences en vitamine $\mathrm{B}_{12}$ avec test de Schilling normal ou syndrome de nondissociation de la vitamine $\mathrm{B}_{12}$ de ses protéines porteuses chez le sujet âgé. Etude de 60 patients," La Revue de Médecine Interne, vol. 24, no. 4, pp. 218-223, 2003.

[24] R. Carmel, I. Aurangzeb, and D. Qian, "Associations of foodcobalamin malabsorption with ethnic origin, age, Helicobacter pylori infection, and serum markers of gastritis," The American Journal of Gastroenterology, vol. 96, no. 1, pp. 63-70, 2001.

[25] K. Kaptan, C. Beyan, A. U. Ural, et al., "Helicobacter pylori-Is it a novel causative agent in vitamin $\mathrm{B}_{12}$ deficiency?" Archives of Internal Medicine, vol. 160, no. 9, pp. 1349-1353, 2000.

[26] C. W. Howden, "Vitamin $B_{12}$ levels during prolonged treatment with proton pump inhibitors," Journal of Clinical Gastroenterology, vol. 30, no. 1, pp. 29-33, 2000. 
[27] E. Andrès, E. Noel, and M. Ben Abdelghani, "Vitamin $B_{12}$ deficiency associated with chronic acid suppression therapy," The Annals of Pharmacotherapy, vol. 37, no. 11, p. 1730, 2003.

[28] B. Termanini, F. Gibril, V. E. Sutliff, F. Yu, D. J. Venzon, and R. T. Jensen, "Effect of long-term gastric acid suppressive therapy on serum vitamin $B_{12}$ levels in patients with Zollinger-Ellison syndrome," The American Journal of Medicine, vol. 104, no. 5, pp. 422-430, 1998.

[29] R. T. Jensen, "Consequences of long-term proton pump blockade: insights from studies of patients with gastrinomas," Basic \& Clinical Pharmacology \& Toxicology, vol. 98, no. 1, pp. 4-19, 2006.

[30] W. A. Bauman, S. Shaw, E. Jayatilleke, A. M. Spungen, and V. Herbert, "Increased intake of calcium reverses vitamin $B_{12}$ malabsorption induced by metformin," Diabetes Care, vol. 23, no. 9, pp. 1227-1231, 2000.

[31] E. Andrès, E. Noel, and B. Goichot, "Metformin-associated vitamin $\mathrm{B}_{12}$ deficiency," Archives of Internal Medicine, vol. 162, no. 19, pp. 2251-2252, 2002.

[32] K. W. Liu, L. K. Dai, and W. Jean, "Metformin-related vitamin $\mathrm{B}_{12}$ deficiency," Age and Ageing, vol. 35, no. 2, pp. 200-201, 2006.

[33] E. Andrès, B. Goichot, A.-E. Perrin, S. Vinzio, C. Demangeat, and J.-L. Schlienger, "Sjögren's syndrome: a potential new aetiology of mild cobalamin deficiency," Rheumatology, vol. 40, no. 10, pp. 1196-1197, 2001.

[34] T. S. Dharmarajan, G. U. Adiga, and E. P. Norkus, "Vitamin $\mathrm{B}_{12}$ deficiency: recognizing subtle symptoms in older adults," Geriatrics, vol. 58, no. 3, pp. 30-38, 2003.

[35] E. Andrès, S. Affenberger, J. Zimmer, et al., "Current hematological findings in cobalamin deficiency. A study of 201 consecutive patients with documented cobalamin deficiency," Clinical and Laboratory Haematology, vol. 28, no. 1, pp. 50-56, 2006.

[36] R. Carmel and M. Sarrai, "Diagnosis and management of clinical and subclinical cobalamin deficiency: advances and controversies," Current Hematology Reports, vol. 5, no. 1, pp. 23-33, 2006.

[37] A. Abyad, "Prevalence of vitamin $B_{12}$ deficiency among demented patients and cognitive recovery with cobalamin replacement," Journal of Nutrition, Health and Aging, vol. 6, no. 4, pp. 254-260, 2002.

[38] M. Elia, "Oral or parenteral therapy for $\mathrm{B}_{12}$ deficiency," The Lancet, vol. 352, no. 9142, pp. 1721-1722, 1998.

[39] Z. Bolaman, G. Kadikoylu, V. Yukselen, I. Yavasoglu, S. Barutca, and T. Senturk, "Oral versus intramuscular cobalamin treatment in megaloblastic anemia: a single-center, prospective, randomized, open-label study," Clinical Therapeutics, vol. 25, no. 12, pp. 3124-3134, 2003.

[40] E. Andrès, G. Kaltenbach, E. Noel, et al., "Efficacy of shortterm oral cobalamin therapy for the treatment of cobalamin deficiencies related to food-cobalamin malabsorption: a study of 30 patients," Clinical and Laboratory Haematology, vol. 25, no. 3, pp. 161-166, 2003.

[41] E. Andrès, J.-E. Kurtz, A.-E. Perrin, et al., "Oral cobalamin therapy for the treatment of patients with food-cobalamin malabsorption," The American Journal of Medicine, vol. 111, no. 2, pp. 126-129, 2001.

[42] G. Kaltenbach, M. Noblet-Dick, E. Andrès, et al., "Réponse précoce au traitement oral par vitamine $B_{12}$ chez des sujets âgés hypovitaminiques," Annales de Medecine Interne, vol. 154, no. 2, pp. 91-95, 2003.
[43] E. Andrès, G. Kaltenbach, M. Noblet-Dick, et al., "Hematological response to short-term oral cyanocobalamin therapy for the treatment of cobalamin deficiencies in elderly patients," Journal of Nutrition, Health and Aging, vol. 10, no. 1, pp. 3-6, 2006.

[44] C. C. Butler, J. Vidal-Alaball, R. Cannings-John, et al., "Oral vitamin $B_{12}$ versus intramuscular vitamin $B_{12}$ for vitamin $\mathrm{B}_{12}$ deficiency: a systematic review of randomized controlled trials," Journal of Family Practice, vol. 23, no. 3, pp. 279-285, 2006.

[45] W. B. Slot, F. W. Merkus, S. J. Van Deventer, and G. N. Tytgat, "Normalization of plasma vitamin $\mathrm{B}_{12}$ concentration by intranasal hydroxocobalamin in vitamin $\mathrm{B}_{12}$-deficient patients," Gastroenterology, vol. 113, no. 2, pp. 430-433, 1997.

[46] D. Z. B. van Asselt, F. W. Merkus, F. G. M. Russel, and W. H. L. Hoefnagels, "Nasal absorption of hydroxocobalamin in healthy elderly adults," British Journal of Clinical Pharmacology, vol. 45, no. 1, pp. 83-86, 1998.

[47] E. Andrès, N. H. Loukili, E. Noel, et al., "Effects of oral crystalline cyanocobalamin $1000 \mu \mathrm{g} / \mathrm{d}$ in the treatment of pernicious anemia: an open-label, prospective study in ten patients," Current Therapeutic Research, vol. 66, no. 1, pp. 1322, 2005.

[48] J. Vidal-Alaball, C. C. Butler, R. Cannings-John, et al., "Oral vitamin $B_{12}$ versus intramuscular vitamin $B_{12}$ for vitamin $B_{12}$ deficiency," Cochrane Database of Systematic Reviews, vol. 20, no. 3, Article ID CD004655, 2005.

[49] S. J. P. M. Eussen, L. C. P. G. M. de Groot, R. Clarke, et al., "Oral cyanocobalamin supplementation in older people with vitamin $\mathrm{B}_{12}$ deficiency: a dose-finding trial," Archives of Internal Medicine, vol. 165, no. 10, pp. 1167-1172, 2005.

[50] M. Roth and I. Orija, "Oral vitamin $B_{12}$ therapy in vitamin $B_{12}$ deficiency," The American Journal of Medicine, vol. 116, no. 5, p. 358, 2004.

[51] I. D. Graham, N. Jette, J. Tetroe, N. Robinson, S. Milne, and S. L. Mitchell, "Oral cobalamin remains medicine's best kept secret," Archives of Gerontology and Geriatrics, vol. 44, no. 1, pp. 49-59, 2007.

[52] L. R. Solomon, "Disorders of cobalamin (vitamin $\mathrm{B}_{12}$ ) metabolismml: emerging concepts in pathophysiology, diagnosis and treatment," Blood Reviews, vol. 21, no. 3, pp. 113130, 2007.

[53] L. R. Solomon, "Cobalamin-responsive disorders in the ambulatory care setting: unreliability of cobalamin, methylmalonic acid, and homocysteine testing," Blood, vol. 105, no. 3, pp. 978-985, 2005.

[54] E. Andrès, L. Federici, S. Affenberger, et al., " $B_{12}$ deficiency: a look beyond pernicious anemia," Journal of Family Practice, vol. 56, no. 7, pp. 537-542, 2007. 


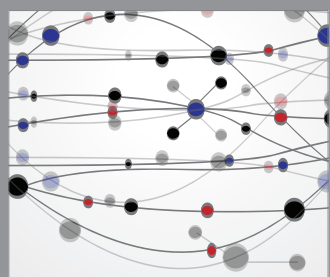

The Scientific World Journal
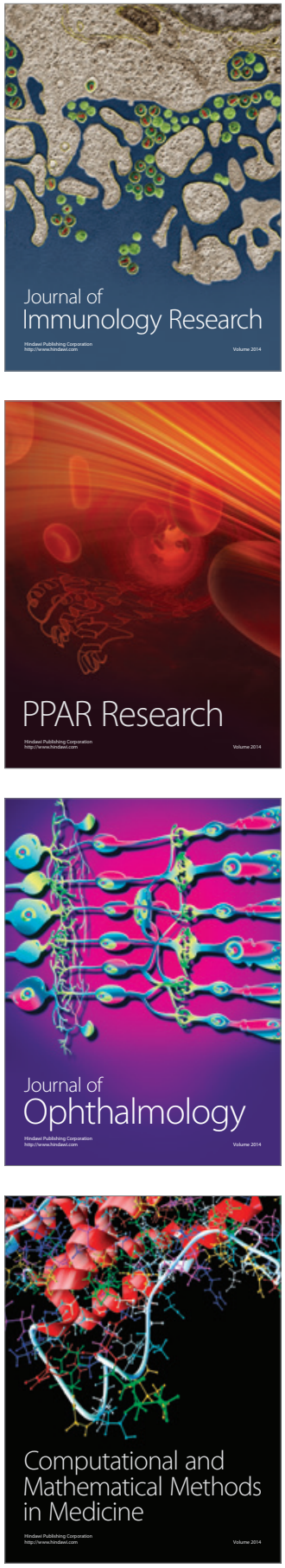

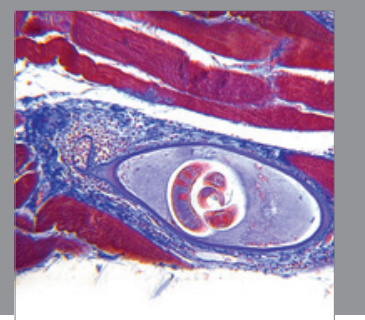

Gastroenterology

Research and Practice
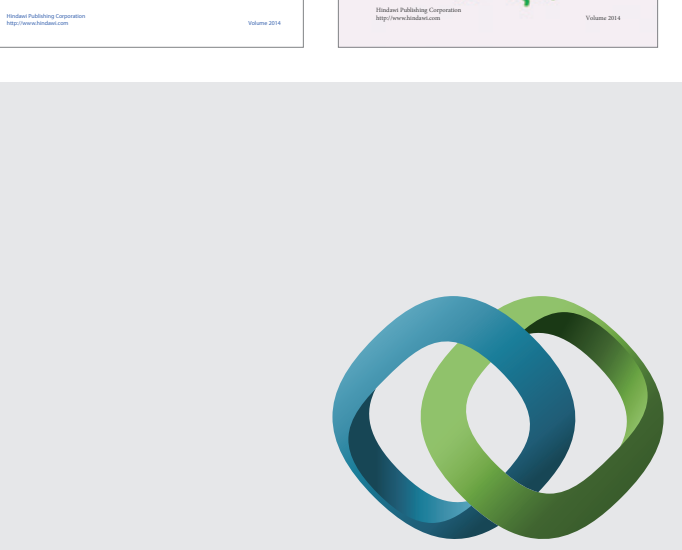

\section{Hindawi}

Submit your manuscripts at

http://www.hindawi.com
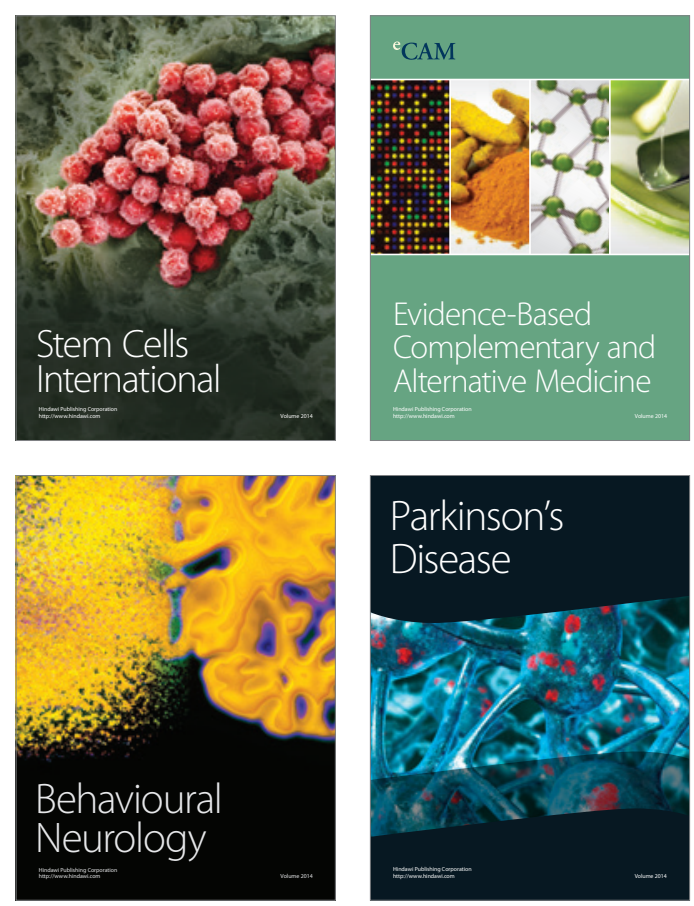

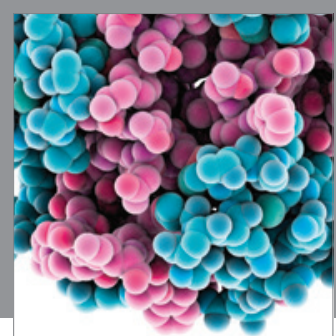

Journal of
Diabetes Research

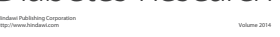

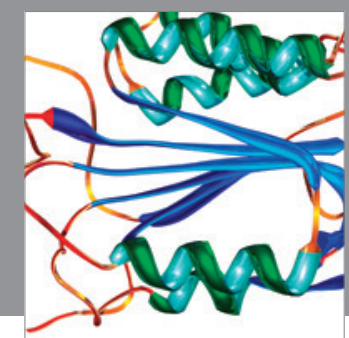

Disease Markers
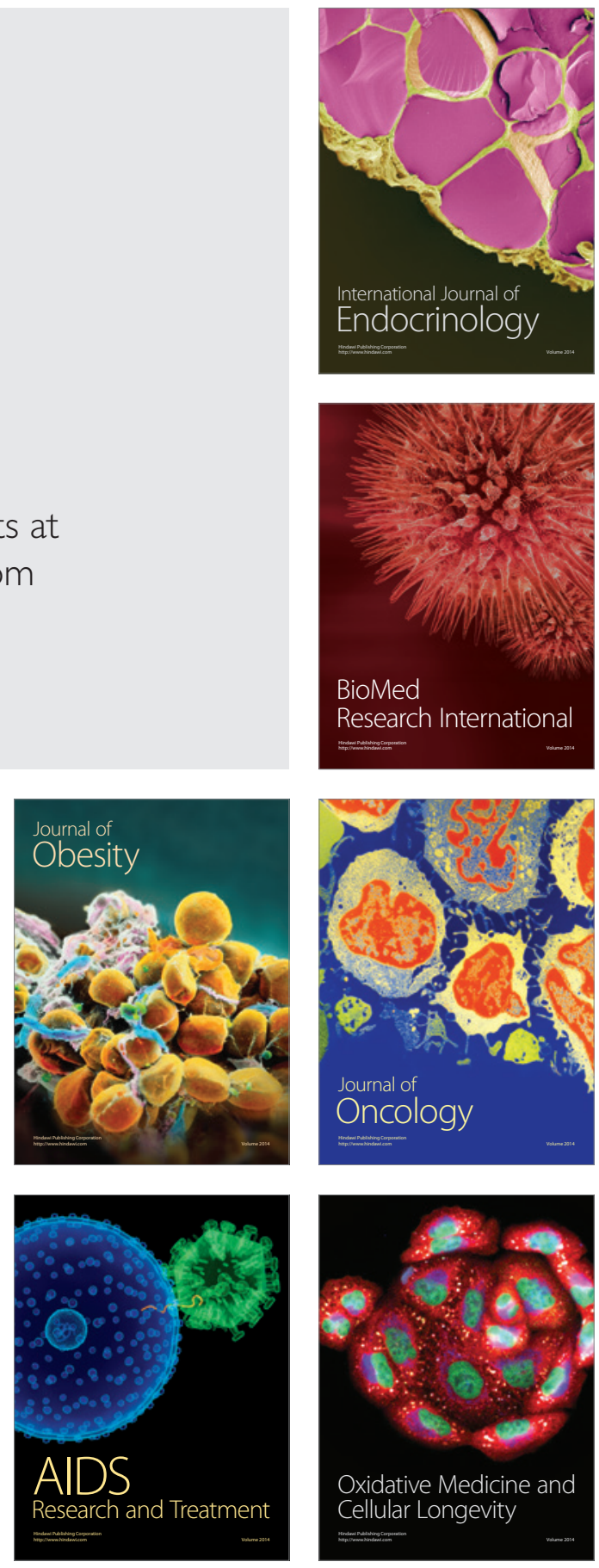